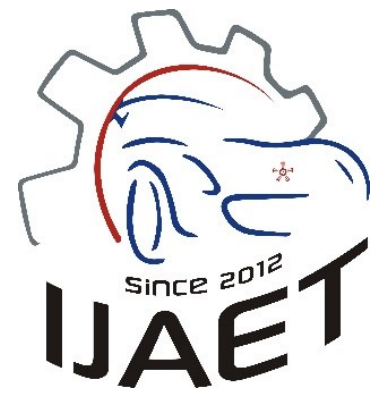

e-ISSN: 2146 - 9067

International Journal of Automotive

Engineering and Technologies

journal homepage:

https://dergipark.org.tr/en/pub/ijaet

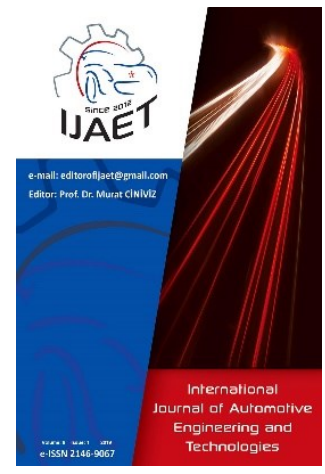

Original Research Article

\title{
Effect of taper angle on crashworthiness performance in hybrid tubes
}

\author{
Murat Altın \\ Department of Automotive Engineering, Faculty of Technology, Gazi University, Ankara, 06590, Turkey
}

\section{ARTICLE INFO}

* Corresponding author maltin@gazi.edu.tr

Received: Oct 28, 2019

Accepted: Dec 19, 2019

Published by Editorial Board Members of IJAET

(C) This article is distributed by Turk Journal Park System under the CC 4.0 terms and conditions.

\begin{abstract}
The present paper dealt with the finite element analysis (FE) analyzing the taper angle design of aluminum/E-glass fiber reinforced polymer hybrid tubes. This study investigated the crushing characteristics involving peak crush force (PCF), crush force efficiency (CFE) and specific energy absorption (SEA) capacity of thirty different configurations of hybrid tubes. Three types of geometries were studied numerically, including circular, square and hexagonal. The structures evaluated included circular hybrid tubes fabricated with aluminum alloy and composite. The hybrid structures were subjected to axial impact loads using a $750-\mathrm{kg}$ rigid impactor with an initial velocity of $15 \mathrm{~m} / \mathrm{s}$. It was found that the crashworthiness performance increased with increasing taper angle. The SEA and CFE values of the circular hybrid tube with a $10^{\circ}$ taper angle were high in the other square and hexagonal hybrid tubes. That hybrid structure can preferable as impact energy absorber due to the ability to withstand axial impact loads effectively.
\end{abstract}

Keywords: Hybrid tubes, Crashworthiness, Peak crush force, Crush force efficiency, Specific energy absorption

\section{Introduction}

Energy absorbing components are important passive safety system elements. These structures are placed between the buffer and the chassis. The cross section geometry and materials of energy absorber structures are various, so, investigating this subject is the aim of many studies.

Metal and composite structures are used in automotive components to absorb substantial amount of deformation energy. Deformation behavior of the metal structures, mostly used in automotive bodies, has been well investigated experimentally $[1,2]$, numerically $[3,4]$ and analytically $[5,6]$. Composites have wide applications in automotive [7-9], racing car $[10,11]$, aerospace $[12,13]$ and spacecraft industry $[14,15]$. The composite tubes are used to reinforce the metal tubes and enhance its energy absorption capacity. Hybrid tubes are made from several layers of composites and metals. As an efficient energy absorbing structure, hybrid tubes are widely studied by researchers in recent years.

Researchers have conducted numerical and experimental studies on hybrid tubes of various 
cross-sectional geometries. Hybrid tubes can have different geometry profiles, such as circular tubes [16,17], square tubes $[18,19]$, corrugated tubes [20,21] and tapered tubes $[22,23]$. Kathiresan et al. investigated the low velocity axial impact and quasi-static loading deformation behavior of fiber metal laminated hybrid conical frusta in Ref. [24,25]. Reuter and Tröster [26] investigated the crashworthiness of aluminum and carbon fiber reinforced polymer (CFRP) hybrid tubes. They found that hybrid tubes showed remarkable lightweight potential, and the special energy absorption of the hybrid tubes was $37 \%$ higher than that of pure metal tubes. Zhu et al. [27] researched the absorbed energy capacity of composite, metal and metal/composite hybrid tubes under axial and oblique crushing loading. They found that different crush loading angles have effect on the crash performance of hybrid and other tubes. Mirzaei et al [28] studied circular hybrid tubes under axial crushing loading. They found that hybrid tubes have more energy absorption capacity in comparison to bare metal tubes. Energy absorbing capacity of axial crushing of hybrid tubes around aluminum tubes were numerically investigated by El-Hage et al. [29]. They found that the SEA capacity of the E-glass fiber-epoxy composite tubes was higher than those the other tubes. Costas et al [30] compared the energy absorption of different structures hybrid tubes with tube made of steel, in their study, they found that crashworthiness performance of glass-fiber reinforced polyamide was higher than hybrid tubes. Esnaola et al. [31] had examined quasi-static compression test to study semi-hexagonal crosssection composite fibers. They found that the highest energy absorption values of nearly 30 $\mathrm{kJ} / \mathrm{kg}$. Hu et al. [32] investigated the deformation characteristics and crashworthiness performance of hybrid tubes. Their results showed that the hybrid tubes the significantly affects the crashworthiness performance and energy absorption capacity. Zhou et al. [33] investigated the crashworthiness performance of carbon fiber-reinforced dual-phase epoxypolyurea hybrid composite tubes. They showed that the crashworthiness performance of carbonfiber reinforced epoxy hybrid tubes is greater than that of other tubes. Song et al [34] experimentally investigated the quasi-static and dynamic impact test on pure metal and FRP metallic structures. They identified four typical collapse modes for tubes including: compound diamond, compound fragmentation, delamination and catastrophic failure.

In the present paper, the effects of taper angle on the crashworthiness performance of hybrid circular, square and hexagonal tubes were numerically investigated. The new design hybrid tube is proved to be a perfect crashworthiness performance with low peak crash force and very high crush force efficiency. It should also be noted that the effect of tapering on hybrid tubes has not been investigated yet in the open literature, and this paper presents a novel contribution in this subject.

\section{Problem Description}

Thin-walled hybrid tubes having circular, square and hexagonal cross-sections types are focused in this study. The hybrid tubes that were used in the FE analysis contained circular, square and hexagonal cross section. Those hybrid tubes were made of steel, aluminum and composite structure with a wall thickness of 2 $\mathrm{mm}$ and length $200 \mathrm{~mm}$ (see Figure1.). To research the effect of the taper angle, eleven different taper angle values $\left(0^{\circ}, 1^{\circ}, 2^{\circ}, 3^{\circ}, 4^{\circ}, 5^{\circ}, 6^{\circ}, 7^{\circ}, 8^{\circ}, 9^{\circ}\right.$ and $\left.10^{\circ}\right)$ are used. The abbreviation CSCA denotes the circular steel/composite/aluminum models, SSCA denotes the square steel/composite/aluminum models, whereas HSCA denotes hexagonal steel/composite/aluminum models.
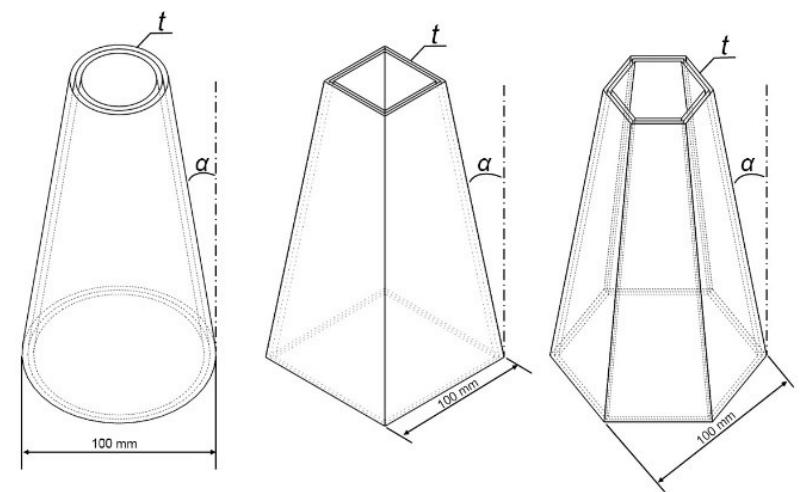

Figure 1. Geometrical configuration

Different parameters have been introduced in FE analysis to evaluate the crashworthiness performance of the structures. The main parameters included in this paper are listed below:

- $\quad$ total energy absorption $\left(T_{E}\right)$ 
- $\quad$ specific energy absorption (SEA)

- $\quad$ mean crush force $(M C F)$

- $\quad$ peak crush force $(P C F)$

- $\quad$ crush force efficiency $(C F E)$

Total energy absorption $\left(T_{E}\right)$ is the area under the force versus displacement curve. $T_{E}$ is calculated from:

$T_{E}=\int P(s) d s$

where the parameter $P$ is the force and $d s$ is the cut-off displacement.

The specific energy absorption ( $S E A)$ is defined as the $T_{E}$ per unit mass $(m)$ of the profile and is given by:

$S E A=\frac{T_{E}}{m}$

The mean crush force $(M C F)$ can be determined by dividing the $T_{E}$ by the displacement $(L)$, and is given by:

$$
M C F=\frac{T_{E}}{L}
$$

During the crash, the maximum impact force point gives the peak crush force $(P C F)$,

$P C F=\max (F(s))$

The crush force efficiency $(C F E)$ is the $M C F$ divided by the $P C F$, or:

$$
C F E=\frac{M C F}{P C F}
$$

They are all very important in the crashworthiness criteria of energy absorber tubes. It is desirable that the $P C F$ is low $S E A$ and $C F E$ are at the highest level.

\section{Finite Element Modeling}

In this study, Ls-Dyna was used to perform all simulations of finite element analysis. The approximate mesh size is set at $3 \mathrm{~mm}$. The hybrid tubes are fixed on a rigid wall where it is impacted by an impact mass of $750 \mathrm{~kg}, 15 \mathrm{~m} / \mathrm{s}$ impact velocity as shown in Figure 2. For the composite tube, E-glass/PET199 composite layup was chosen with materials properties listed in Table 1. Mechanical properties of the steel and aluminum tube were entered in the Ls-
Dyna in accordance with the data shown in Table 2. extracted from the engineering stressstrain curve.

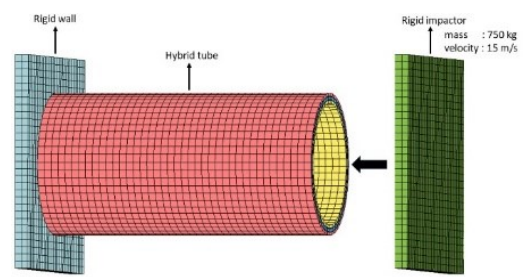

Figure 2. Finite element model of hybrid model

Table 1. Material properties of laminate composite

\begin{tabular}{|c|c|c|}
\hline Property & Description & Value \\
\hline$\rho$ & Density & $2.0 \mathrm{~g} / \mathrm{cm}^{3}$ \\
\hline$E_{a}$ & $\begin{array}{l}\text { Modulus in longitudinal (fiber) } \\
\text { direction }\end{array}$ & $37.9 \mathrm{GPa}$ \\
\hline$E_{b}=E_{c}$ & Modulus in transverse direction & $11.5 \mathrm{GPa}$ \\
\hline$G_{12}$ & Shear modulus & $4.5 \mathrm{GPa}$ \\
\hline$v_{12}$ & Major Poisson's ratio & 0.29 \\
\hline$v_{21}$ & Minor Poisson's ratio & 0.0811 \\
\hline$X_{t}$ & Longitudinal tensile strength & $936 \mathrm{MPa}$ \\
\hline$X_{c}$ & $\begin{array}{l}\text { Longitudinal compressive } \\
\text { strength }\end{array}$ & $484 \mathrm{MPa}$ \\
\hline$Y_{t}$ & Transverse tensile strength & $25.7 \mathrm{MPa}$ \\
\hline$Y_{c}$ & Transverse compressive strength & $143 \mathrm{MPa}$ \\
\hline$S_{c}$ & Shear strength & 16.1 MPa \\
\hline$S_{b}$ & Inter-laminar shear strength & $62.6 \mathrm{MPa}$ \\
\hline$V_{f}$ & Fiber volume fraction & $70 \%$ \\
\hline
\end{tabular}
material E-glass/PET199

Table 2. Material properties of steel and aluminum

\begin{tabular}{lll}
\hline \multicolumn{2}{c}{ Steel } \\
\hline Property & Description & Value \\
\hline$\rho$ & Density & $7.850 \mathrm{~g} / \mathrm{cm}^{3}$ \\
$E$ & Young modulus & $210 \mathrm{GPa}$ \\
$v$ & Poisson's ratio & 0.33 \\
$\sigma_{y}$ & Yield strength & $304 \mathrm{MPa}$ \\
\hline \multicolumn{3}{c}{ Aluminum } \\
\hline Property & Description & Value \\
\hline$\rho$ & Density & $2.800 \mathrm{~g} / \mathrm{cm}^{3}$ \\
$E$ & Young modulus & $70 \mathrm{GPa}$ \\
$v$ & Poisson's ratio & 0.33 \\
$\sigma_{y}$ & Yield strength & $250 \mathrm{MPa}$ \\
\hline
\end{tabular}

The dynamic and static coefficients of friction were chosen 0.3 and 0.2 , respectively. The contact between the rigid impactor and the hybrid tube is AUTOMATIC_NODE_TO_SURFACE_CON TACT.

AUTOMOTIC_SINGLE_SURFACE_CONTA CT_contact is applied between the hybrid tubes. The contact between the hybrid tube and the rigid wall is $\mathrm{A}$ AUTOMATIC_NODE_TO_SURFACE_CON 
TACT algorithm. Belytscko-Tsay shell element with five integration points is chosen. However, material of the structures (aluminum and steel) was modeled by MAT_MODIFIEDPIECEWISE- LINEAR-PLASTICITY model MAT-24 in Ls-Dyna. Material applied for the composite tube is composite, which is modeled with the MAT_ENHANCED_COMPOSITE_DAMAG E model MAT-54 in LS-DYNA. The postprocessor LSPREPOST is used for visualization and data acquisition.

\section{Experimental Validation}

Validation of the experimental results is critical for the acceptance of such simulations. This section describes the results of numerical FE simulation of composite tubes are compared with the experimental results. Zhang et al. have carried out experiments for composite circular tube under axial loading [35]. In their experiments they adopted composite Eglass/PET199 structures extruded tubes with lengths of $100 \mathrm{~mm}$, inner diameter of $80 \mathrm{~mm}$ and wall thickness $2.4 \mathrm{~mm}$. The comparison of the FE analysis results obtained in this study and the results presented in [35] are given in Table 3. Fig. 3. compares the force-displacement curve results obtained from the experimental [35] and finite element result.

This numerical simulation was compared to metal tubes (steel) sets of the numerical analysis result by Nagel [36]. Table 4. presents crashworthiness parameters of the steel specimens modeled in the studies. Figure 4. depicts a comparison of the deformed shape between FE analysis and experimental result at crush distance of $200 \mathrm{~mm}$. The finite element results demonstrate that there is a perfect compatibility between numerical results of this paper and mentioned references.

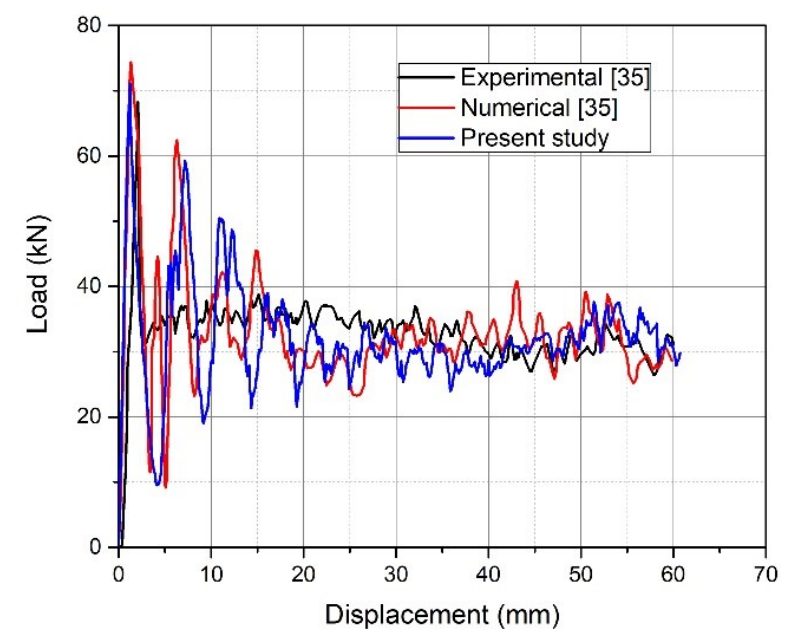

Figure 3. Validation of load-displacement curve of composite tube

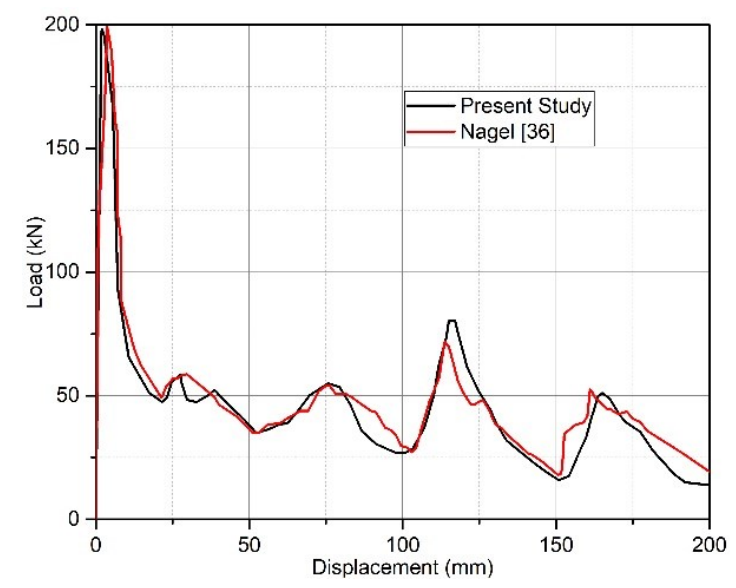

Figure 4. Validation of load-displacement curve of steel tube

\begin{tabular}{|c|c|c|c|c|}
\hline & Crush distance $(\mathrm{mm})$ & $T_{E}(\mathrm{~kJ})$ & $P C F(k \mathbf{N})$ & $S E A(k j / k g)$ \\
\hline Zhang [35] & 60 & 1.968 & 68.26 & 14.77 \\
\hline Zhang [35] & 60 & 1.927 & 74.36 & 14.47 \\
\hline Present study & 60 & 1.924 & 71.10 & 14.44 \\
\hline
\end{tabular}

Table 4. Comparison of FE analysis and experimental results for steel tube

\begin{tabular}{lcccc}
\hline & Crush distance (mm) & $\boldsymbol{T}_{\boldsymbol{E}}(\mathbf{k J})$ & $\boldsymbol{P C F}(\mathbf{k N})$ & $\boldsymbol{S E A}(\mathbf{k j} / \mathbf{k g})$ \\
\hline Nagel [36] & 200 & 9.036 & 199.49 & 8.53 \\
Present study & 200 & 8.922 & 198.72 & 8.42 \\
\hline
\end{tabular}

\section{Result and Discussion}

In this section, various angles were used for different types of analyses so as to find out the effects of taper angle. The results of the FE analysis are given in Table 5, Table 6 and Table
7 , respectively. Table 5 . The effect of taper angle on the crashworthiness performance of circular hybrid tubes.

For all the hybrid tubes, the increase in SEA and CFE is almost directly proportional to the increase in tube taper angle. For example, for the 
CSCA hybrid tube, the CFE increased from 0.45 to 0.70 when the taper angle increased from 0 to 10 (see Figure 5., Figure 6. and Figure 7.). As for the SEA, it increased from $98.19 \mathrm{~kJ} / \mathrm{kg}$ to $136.47 \mathrm{~kJ} / \mathrm{kg}$ when the taper angle increased from 0 to 10 (see Figure 8., Figure 9. and Figure
10.).

The increase in the angle contributed positively to both SEA and CFE. It is clear that all hybrid tapered tubes generally have better SEA and CFE than the straight hybrid tubes, especially at large load angles.

Table 5. The effect of taper angle on the crashworthiness performance of circular hybrid tubes

\begin{tabular}{cccccccc}
\hline Run & $\begin{array}{c}\text { Crush } \\
\text { distance }(\mathbf{m m})\end{array}$ & $\boldsymbol{T}_{\boldsymbol{E}}(\mathbf{k J})$ & $\boldsymbol{P C F}(\mathbf{k N})$ & $\begin{array}{c}\boldsymbol{M C F} \\
(\mathbf{k N})\end{array}$ & $\boldsymbol{C F} \boldsymbol{M a s s}(\mathbf{k g})$ & $\begin{array}{c}\boldsymbol{S E A} \\
(\mathbf{k j} / \mathbf{k g})\end{array}$ \\
\hline CSCA0 & 120 & 32.993 & 615.98 & 274.94 & 0.45 & 0.336 & 98.19 \\
CSCA1 & 120 & 33.316 & 573.23 & 277.63 & 0.48 & 0.324 & 102.83 \\
CSCA2 & 120 & 34.751 & 525.20 & 289.59 & 0.55 & 0.311 & 111.74 \\
CSCA3 & 120 & 31.382 & 489.26 & 261.52 & 0.53 & 0.299 & 104.96 \\
CSCA4 & 120 & 32.022 & 451.92 & 266.85 & 0.59 & 0.287 & 111.57 \\
CSCA5 & 120 & 32.134 & 422.51 & 267.78 & 0.63 & 0.275 & 116.85 \\
CSCA6 & 120 & 30.334 & 395.14 & 252.78 & 0.64 & 0.263 & 115.34 \\
CSCA7 & 120 & 29.803 & 375.22 & 248.36 & 0.66 & 0.251 & 118.74 \\
CSCA8 & 120 & 29.667 & 379.52 & 247.23 & 0.65 & 0.239 & 124.13 \\
CSCA9 & 120 & 29.377 & 360.45 & 244.81 & 0.68 & 0.227 & 129.41 \\
CSCA10 & 120 & 29.340 & 348.98 & 244.50 & 0.70 & 0.215 & 136.47 \\
\hline
\end{tabular}

Table 6. The effect of taper angle on the crashworthiness performance of square hybrid tubes

\begin{tabular}{cccccccc}
\hline Run & $\begin{array}{c}\text { Crush } \\
\text { distance }(\mathbf{m m})\end{array}$ & $\boldsymbol{T}_{\boldsymbol{E}}(\mathbf{k J})$ & $\boldsymbol{P C F}(\mathbf{k N})$ & $\begin{array}{c}\boldsymbol{M C F} \\
(\mathbf{k N})\end{array}$ & $\boldsymbol{C F E}$ & Mass $(\mathbf{k g})$ & $\begin{array}{c}\boldsymbol{S E A} \\
(\mathbf{k j} / \mathbf{k g})\end{array}$ \\
\hline SSCA0 & 120 & 29.461 & 794.92 & 245.51 & 0.31 & 0.428 & 68.83 \\
SSCA1 & 120 & 28.243 & 728.52 & 235.36 & 0.32 & 0.412 & 68.55 \\
SSCA2 & 120 & 30.415 & 679.15 & 253.46 & 0.37 & 0.397 & 76.61 \\
SSCA3 & 120 & 29.691 & 625.58 & 247.43 & 0.40 & 0.381 & 77.93 \\
SSCA4 & 120 & 29.461 & 579.00 & 245.51 & 0.42 & 0.366 & 80.49 \\
SSCA5 & 120 & 28.243 & 519.77 & 235.36 & 0.45 & 0.361 & 78.24 \\
SSCA6 & 120 & 27.078 & 610.90 & 225.65 & 0.37 & 0.335 & 80.83 \\
SSCA7 & 120 & 26.373 & 545.81 & 219.78 & 0.40 & 0.320 & 82.42 \\
SSCA8 & 120 & 26.382 & 481.07 & 219.85 & 0.46 & 0.305 & 86.50 \\
SSCA9 & 120 & 25.674 & 408.51 & 213.95 & 0.52 & 0.289 & 88.84 \\
SSCA10 & 120 & 24.370 & 344.71 & 203.08 & 0.59 & 0.274 & 88.94 \\
\hline
\end{tabular}

Table 7. The effect of taper angle on the crashworthiness performance of hexagonal hybrid tubes

\begin{tabular}{cccccccc}
\hline Run & $\begin{array}{c}\text { Crush } \\
\text { distance }(\mathbf{m m})\end{array}$ & $\boldsymbol{T}_{\boldsymbol{E}}(\mathbf{k J})$ & $\boldsymbol{P C F}(\mathbf{k N})$ & $\begin{array}{c}\boldsymbol{M C F} \\
(\mathbf{k N})\end{array}$ & $\boldsymbol{C F E}$ & $\mathbf{M a s s}(\mathbf{k g})$ & $\begin{array}{c}\boldsymbol{S E A} \\
(\mathbf{k j} / \mathbf{k g})\end{array}$ \\
\hline HSCA0 & 120 & 33.373 & 676.35 & 278.11 & 0.41 & 0.370 & 90.20 \\
HSCA1 & 120 & 33.744 & 632.12 & 281.20 & 0.44 & 0.357 & 94.52 \\
HSCA2 & 120 & 32.687 & 590.44 & 272.39 & 0.46 & 0.344 & 95.02 \\
HSCA3 & 120 & 32.111 & 547.72 & 267.59 & 0.49 & 0.330 & 97.31 \\
HSCA4 & 120 & 31.336 & 511.52 & 261.13 & 0.51 & 0.317 & 98.85 \\
HSCA5 & 120 & 30.767 & 476.52 & 256.39 & 0.54 & 0.304 & 101.21 \\
HSCA6 & 120 & 29.762 & 424.49 & 248.02 & 0.58 & 0.290 & 102.63 \\
HSCA7 & 120 & 29.535 & 382.64 & 246.13 & 0.64 & 0.277 & 106.62 \\
HSCA8 & 120 & 28.609 & 354.50 & 238.41 & 0.67 & 0.264 & 108.37 \\
HSCA9 & 120 & 27.756 & 336.82 & 231.30 & 0.69 & 0.251 & 110.58 \\
HSCA10 & 120 & 26.018 & 313.93 & 222.65 & 0.69 & 0.237 & 109.78 \\
\hline
\end{tabular}

In spite of that both of $\mathrm{T}_{\mathrm{E}}$ and PCF values are decreasing by taper angle increasing. For instance, for HSCA hybrid tube, $\mathrm{T}_{\mathrm{E}}$ increases from $33.373 \mathrm{~kJ}$ to $33.744 \mathrm{~kJ}$ when the taper angle increases from 0 to 1 , but reduces to $30.767 \mathrm{~kJ}$ and then to $26.718 \mathrm{~kJ}$ when the taper angle further increases to 5 and then to 10 . This change depends on the deformation shape of the hybrid tubes. The change in the amount of total energy absorption capacity depending on the taper angle is given in Figure 11., Figure 12. and Figure 13. Similarly, an increase in the taper angle from 1 to 10 resulted in a decrease in the PCF value (see Figure 14., Figure 15. and Figure 
16.). The taper angle increased the CFE even more, even though it reduced the total energy absorption.

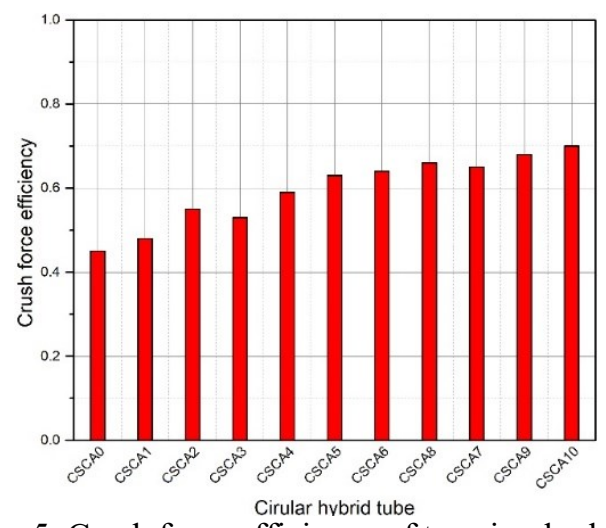

Figure 5. Crush force efficiency of ten circular hybrid tubes

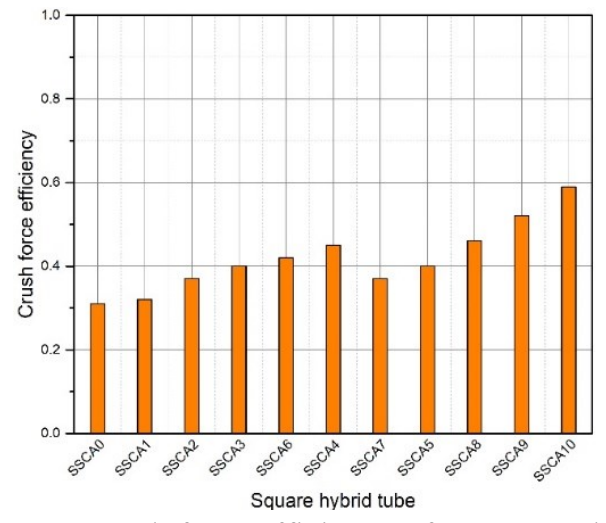

Figure 6. Crush force efficiency of ten square hybrid tubes

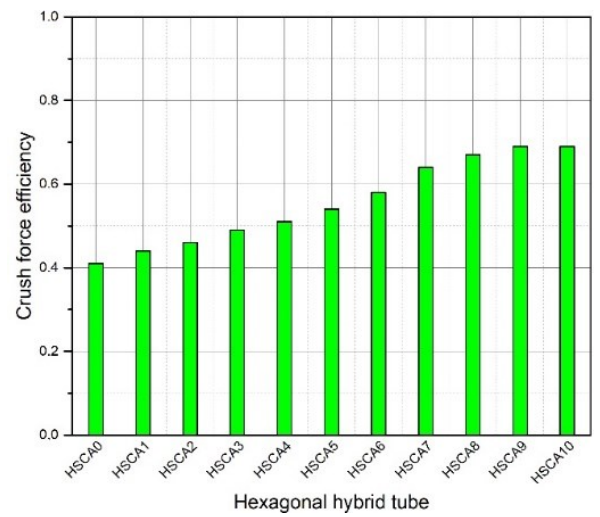

Figure 7. Crush force efficiency of ten hexagonal hybrid tubes

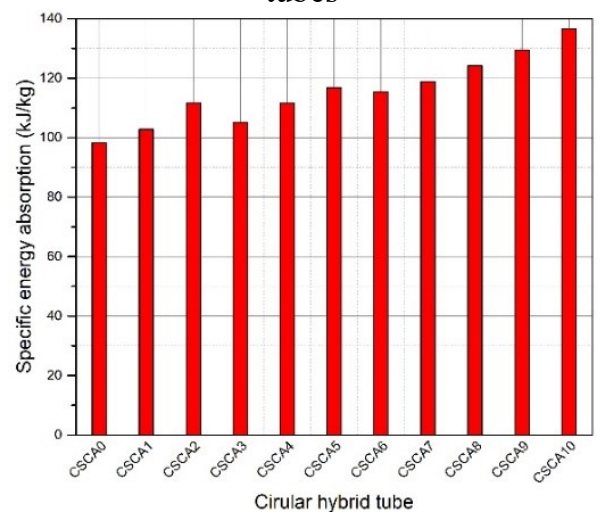

Figure 8. Specific energy absorption of ten circular

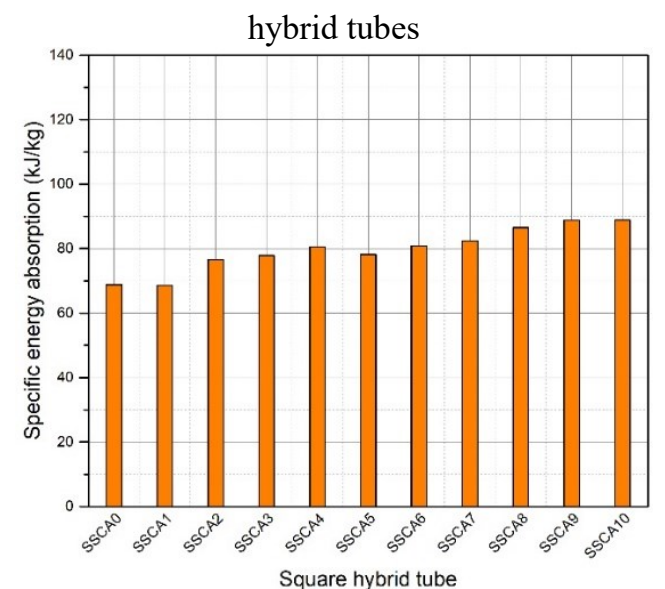

Figure 9. Specific energy absorption of ten square hybrid

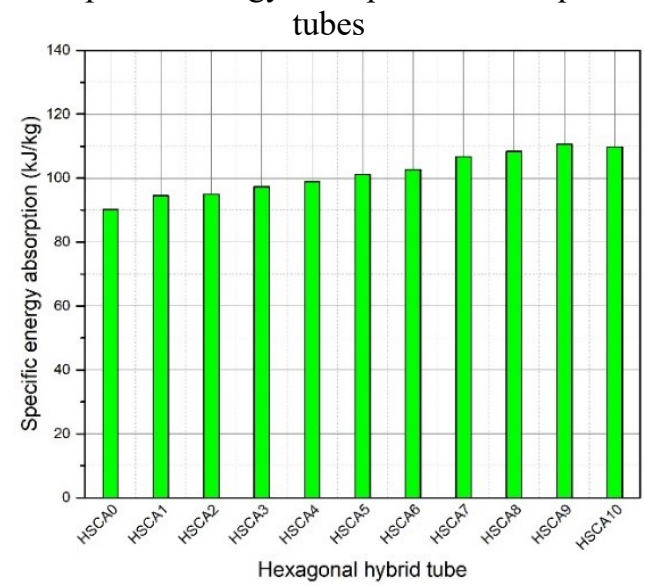

Figure 10. Specific energy absorption of ten hexagonal hybrid tubes

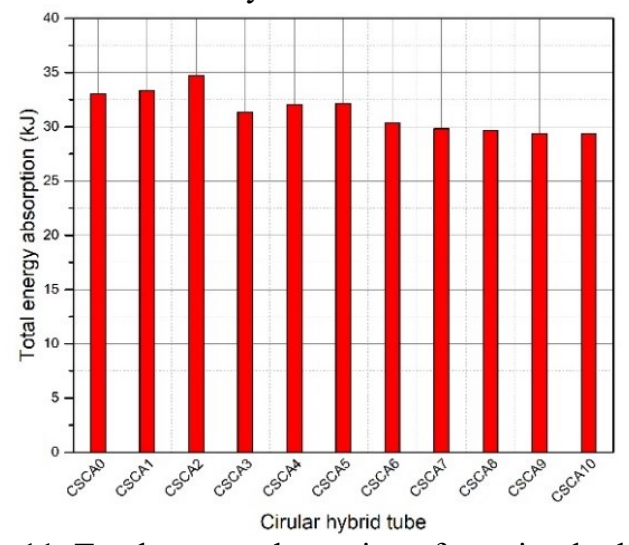

Figure 11. Total energy absorption of ten circular hybrid tubes

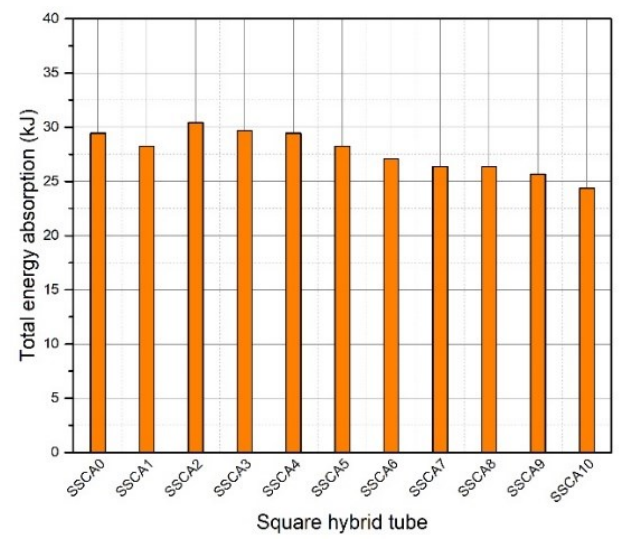

Figure 12. Total energy absorption of ten square hybrid tubes 


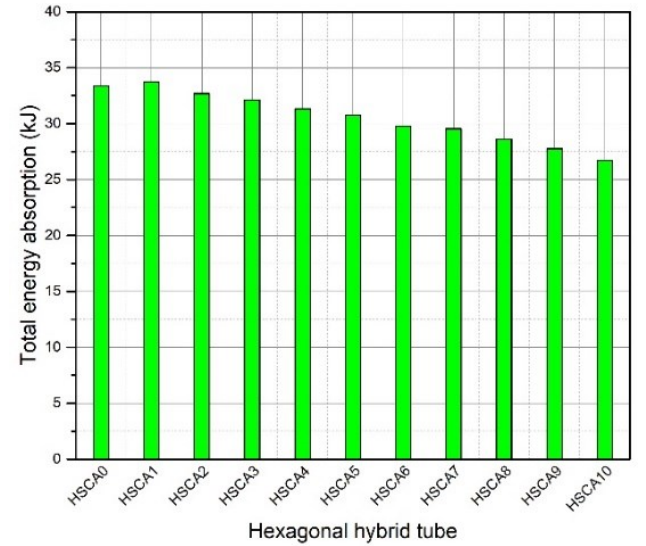

Figure 13. Total energy absorption of ten hexagonal hybrid tubes

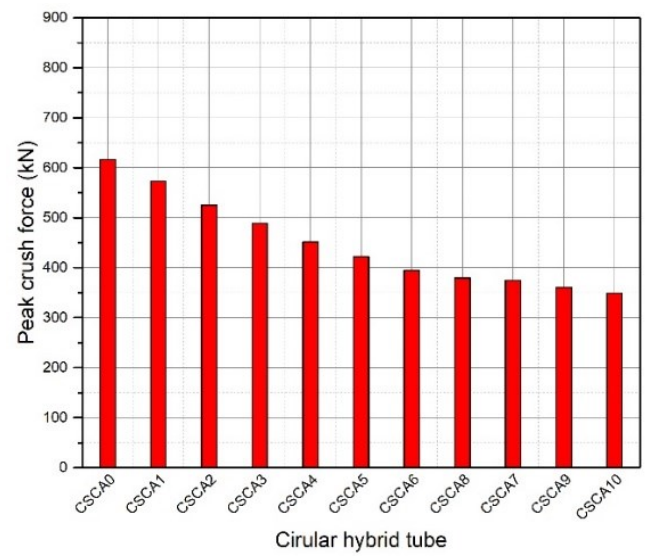

Figure 14. Peak crush force of ten circular hybrid tubes

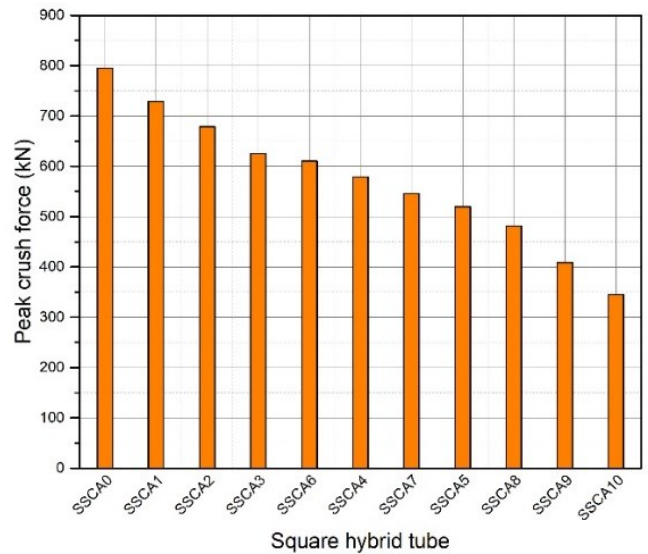

Figure 15. Peak crush force of ten square hybrid tubes

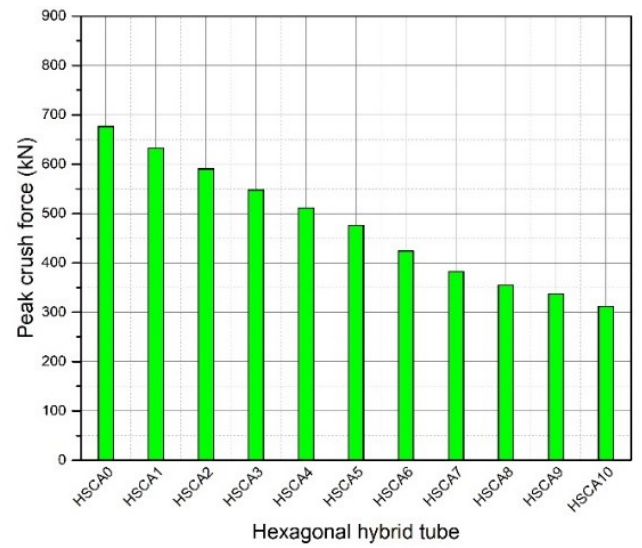

Figure 16. Peak crush force of ten hexagonal hybrid tubes

\section{Conclusion}

This study investigates the crashworthiness of hybrid tubes under dynamic axial impact. From the results obtained, the following conclusions were drawn:

- Increasing the taper angle from $0^{\circ}$ to $10^{\circ}$ for the circular, square and hexagonal hybrid tubes gives a decrease in PCF of around $50 \%$ for all geometries.

- Taper angle has significant effect on the TE of hybrid tubes. For circular and square hybrid tubes, TE increased to the point and then continued to decline. For hexagonal, TE continued to decrease as the taper angle increased.

- It is found for circular, square and hexagonal cross-section hybrid tubes that as the taper angle step by step increases from $0^{\circ}$ to $10^{\circ}$, $\mathrm{CFE}$ and SAE increase.

- $\quad$ CSCA10 with $10^{\circ}$ have highest CFE and SEA under axial impact loading. Specifically, the CFE of the CSCA10 hybrid tube was $226 \%$ higher than that of the SSCA0 hybrid tube. Similarly, the SEA of the CSCA10 hybrid tube was $199 \%$ higher than that of the SSCA1 hybrid tube.

\section{References}

1. Mamalis A.G., Manolakos D.E., Loannidis M.B., and P.K. Kostazos, "Axial collapse of hybrid square sandwich composite tubular components with corrugated core: Experimental", International Journal of Crashworthiness, 5(3), 315-332, 2000.

2. Kim H. C., Shin D. K., Lee J. J., and Kwon J. B., "Crashworthiness of aluminum/CFRP square hollow section beam under axial impact loading for crash box application", Composite Structures 112, 1-10, 2014.

3. Mamalis A.G., Manolakos D.E., Loannidis M.B., and Kostazos P.K., "Crushing of hybrid square sandwich composite vehicle hollow bodyshells with reinforced core subjected to axial loading: numerical simulation", Composite Structures, 61 (3), 175-186, 2003.

4. El-Hage H., Mallick P. K., and Zamani N., "Numerical modelling of quasi-static axial crush of square aluminium-composite hybrid tubes", International Journal of Crashworthiness, 9 (6), 653-664, 2004.

5. Shen Q., Wang J., Wang Y., and Wang F., 
"Analytical modelling and design of partially CFRP-wrapped thin-walled circular NCFST stub columns under axial compression", ThinWalled Structures, 144, 106276, 2019.

6. Mamalis A. G., Manolakos D. E., Demosthenous G. A., and Ioannidis M. B., "Analytical modelling of the static and dynamic axial collapse of thin-walled fibreglass composite conical shells", International Journal of Impact Engineering, 19(5-6), 477-492, 1997. 7. Hesse S. H., Lukaszewicz D. J., and Duddeck F., "A method to reduce design complexity of automotive composite structures with respect to crashworthiness", Composite Structures, 129, 236-249, 2015.

8. Jacob G. C., Fellers J. F., Simunovic S., and Starbuck J. M., "Energy absorption in polymer composites for automotive crashworthiness", Journal of composite materials, 36(7), 813-850, 2002.

9. Bouchet J., Jacquelin E., and Hamelin P., "Static and dynamic behavior of combined composite aluminium tube for automotive applications", Composites science and technology, 60 (10), 1891-1900, 2000.

10. Bisagni C., Di Pietro G., Fraschini L., and Terletti D., "Progressive crushing of fiberreinforced composite structural components of a Formula One racing car", Composite structures, 68(4), 491-503, 2005.

11. Wang J., Yang N., Zhao J., Wang D., Wang Y., Li K., and Wang B., "Design and experimental verification of composite impact attenuator for racing vehicles", Composite Structures, 141, 39-49, 2016.

12. Wang K., Kelly D., and Dutton S., "Multiobjective optimisation of composite aerospace structures", Composite Structures, 57(1-4), 141148, 2002.

13. Greenhalgh E., and Hiley M., "The assessment of novel materials and processes for the impact tolerant design of stiffened composite aerospace structures, Composites part A: applied science and manufacturing", 34(2), 151-161, 2003.

14. Morozov E. V., Lopatin A. V., and Taygin V. B., "Design, analysis, manufacture and testing of composite corrugated horn for the spacecraft antenna system", Composite Structures, 136, 505-512, 2016.

15. Lopatin A. V., Morozov E. V., and Shatov A. V., "Axial deformability of the composite lattice cylindrical shell under compressive loading: Application to a load-carrying spacecraft tubular body", Composite Structures, 146, 201-206, 2016.

16. Zhu G., Sun G., Yu H., Li S., and Li Q., "Energy absorption of metal, composite and metal/composite hybrid structures under oblique crushing loading", International Journal of Mechanical Sciences, 135, 458-483, 2018.

17. Zhu G., Sun G., Liu Q., Li G., and Li Q., “On crushing characteristics of different configurations of metal-composites hybrid tubes", Composite Structures, 175, 58-69, 2017. 18. Yu H., Shi H., and Chen S., "A novel multicell CFRP/AA6061 hybrid tube and its structural multiobjective optimization", Composite Structures, 209, 579-589, 2019.

19. Shin K. C., Lee J. J., Kim K. H., Song M. C., and Huh J. S., "Axial crush and bending collapse of an aluminum/GFRP hybrid square tube and its energy absorption capability", Composite structures, 57 (1-4), 279-287, 2002.

20. Sokolinsky V. S., Indermuehle K. C., and Hurtado J. A., "Numerical simulation of the crushing process of a corrugated composite plate", Composites Part A: Applied Science and Manufacturing, 42 (9), 1119-1126, 2011.

21. Mamalis A. G., Manolakos D. E., Loannidis M. B., Kostazos P. K., and Papapostolou D. P., "Axial collapse of hybrid square sandwich composite tubular components with corrugated core: numerical modelling", Composite structures, 58(4), 571-582, 2002.

22. Boria S., Scattina A., and Belingardi G., "Axial energy absorption of CFRP truncated cones", Composite Structures, 130, 18-28. 2015. 23. Zhao X., Zhu G., Zhou C., and Yu Q, "Crashworthiness analysis and design of composite tapered tubes under multiple load cases", Composite Structures, 222, 110920, 2019.

24. Kathiresan M., and Manisekar K., "Axial crush behaviours and energy absorption characteristics of aluminium and E-glass/epoxy over-wrapped aluminium conical frusta under low velocity impact loading", Composite Structures, 136, 86-100, 2016.

25. Kathiresan M., Manisekar K., and Manikandan V., "Crashworthiness analysis of glass fibre/epoxy laminated thin walled composite conical frusta under axial compression", Composite Structures, 108, 584- 
$599,2014$.

26. Reuter C., and Tröster T., "Crashworthiness and numerical simulation of hybrid aluminiumCFRP tubes under axial impact", Thin-Walled Structures, 117, 1-9, 2017.

27. Zhu G., Sun G., Yu H., Li S., and Li Q., "Energy absorption of metal, composite and metal/composite hybrid structures under oblique crushing loading", International Journal of Mechanical Sciences, 135, 458-483, 2018.

28. Mirzaei M., Shakeri M., Sadighi M., and Akbarshahi H., "Experimental and analytical assessment of axial crushing of circular hybrid tubes under quasi-static load", Composite Structures, 94 (6), 1959-1966, 2012.

29. El-Hage H., Mallick P. K., and Zamani N., "A numerical study on the quasi-static axial crush characteristics of square aluminumcomposite hybrid tubes", Composite structures, 73 (4), 505-514, 2006.

30. Costas M., Díaz J., Romera L. E., Hernández S., and Tielas A., "Static and dynamic axial crushing analysis of car frontal impact hybrid absorbers", International Journal of Impact Engineering, 62, 166-181, 2013.

31. Esnaola A., Ulacia I., Aretxabaleta L., Aurrekoetxea J., and Gallego I., "Quasi-static crush energy absorption capability of Eglass/polyester and hybrid E-glassbasalt/polyester composite structures", Materials \& Design, 76, 18-25, 2015.

32. Hu D. Y., Luo M., and Yang J. L., "Experimental study on crushing characteristics of brittle fibre/epoxy hybrid composite tubes", International journal of crashworthiness, 15 (4), 401-412, 2010.

33. Zhou H., Attard T. L., Dhiradhamvit K., Wang Y., and Erdman D., "Crashworthiness characteristics of a carbon fiber reinforced dualphase epoxy-polyurea hybrid matrix composite", Composites Part B: Engineering, 71, 17-27, 2015.

34. Song H. W., Wan Z. M., Xie Z. M., and Du $\mathrm{X}$. W., "Axial impact behavior and energy absorption efficiency of composite wrapped metal tubes", International Journal of Impact Engineering, 24 (4), 385-401, 2000.

35. Zhang Z., Sun W., Zhao Y., and Hou S., "Crashworthiness of different composite tubes by experiments and simulations", Composites Part B: Engineering, 143, 86-95, 2018.

36. Nagel G. M., and Thambiratnam D. P.,
"Dynamic simulation and energy absorption of tapered tubes under impact loading", International Journal of Crashworthiness, 9 (4), 389-399, 2004. 